\title{
Current building strategies in Greenland
}

\author{
Eva B. Møller ${ }^{1, *}$, and Tove Lading ${ }^{1}$ \\ ${ }^{1}$ Department of Civil Engineering, Technical University of Denmark, Denmark
}

\begin{abstract}
Most buildings in Greenland are built within the last 70 years. Within this relatively short period, the building styles have often changed; from small wooden houses in the 50ties to also encompass more industrialised buildings in the 70ties, and later more diverse technics. This paper describes the major tendencies in building construction of today. Apart from an extreme climate, one of the challenges in Greenland is the lack of building materials; almost everything has to be imported. Greenland is an islandoperated community, with no interlinking road grid between towns and settlements. Therefore, everything must be transported by ship or plane. Furthermore, severe mould growth is a big problem. Consequently, three building strategies are currently prevailing. 1) In-situ concrete gables and partitioning walls, and facades with wooden studs. 2) Focus on non-organic material and therefore concrete structures with exterior insulation. 3) Strategies focussing on the process e.g. mainly using prefabricated elements. The paper describes the pro and cons for the different strategies seen in a Greenlandic context. The harsh climate makes Greenland a good test site for assessing new building designs. Furthermore, assessment of sustainability might be very different in Greenland from countries where resources and transportation is very different.
\end{abstract}

\section{Introduction}

Building in Greenland entails several challenges; not only is the climate harsh, it is also an island-operated community. Therefore, hygrothermal as well as process oriented problems must be faced.

\subsection{The Greenlandic setting}

Greenland is the largest island in the world $(2,600 \mathrm{~km}$ from north to south, and 1,050 from east to west), however, most of it is covered with ice, and the people live along the coast. Most of the 56,000 inhabitants live on the west coast, approximately 3,000 people live on the east coast. The capital Nuuk is by far the biggest town with 18,000 inhabitants, the second largest town Sisimiut has 5,600 inhabitants $[1,2]$.

\subsubsection{Climate}

The Greenlandic climate varies; High Arctic in the North, Low Arctic in the middle and southern part, whereas the deep fjords of the south have Sub Arctic climate [1]. In the Building Regulations [3] the energy demands are divided in two zones; north and south of the Polar Circle. To give an idea of the climate Figure 1 illustrates temperature, relative humidity, precipitation and wind speed in Nuuk (west coast, $240 \mathrm{~km}$ south of the Polar Circle) in 2019, based on information from [4]. The wind speed is shown as maximum 10 min values per day, precipitation as $\mathrm{mm}$ per day, while temperature and relative humidity are shown as mean daily values, supplemented with running mean monthly values (smooth lines).

From a building physical point of view, Nuuk is one of the places with the most challenging weather, it is relatively moist, windy and with sudden weather changes, resulting in many temperature shifts between frost and thaw. When the sun shines, the temperature can locally become much higher than shown in Figure 1, resulting in even more shifts between frost and thaw. Also, notice how high wind speed sometimes coincide with high precipitation, another challenging phenomenon.

In other parts of Greenland, the weather is less challenging, in general; the further north the colder, dryer and less windy [1].

\subsubsection{Island-operations}

Having 56,000 inhabitants spread over 17 towns and 57 settlements [5], with large distances of impassable terrain without roads in between, it is necessary to transport materials and workers by either ship or aircraft. This makes building in Greenland very costly and inflexible. It is not possible to commute between towns or settlements on a daily basis, therefore, there might be a shortage on workers in one town and a surplus in another. Furthermore, there are few specialists, these are mainly in the capital, and it is costly to get a specialist to a settlement or even another town. Likewise, if special parts are needed, it can take time and money before they can be provided.

\footnotetext{
* Corresponding author: ebmo@byg.dtu.dk
} 

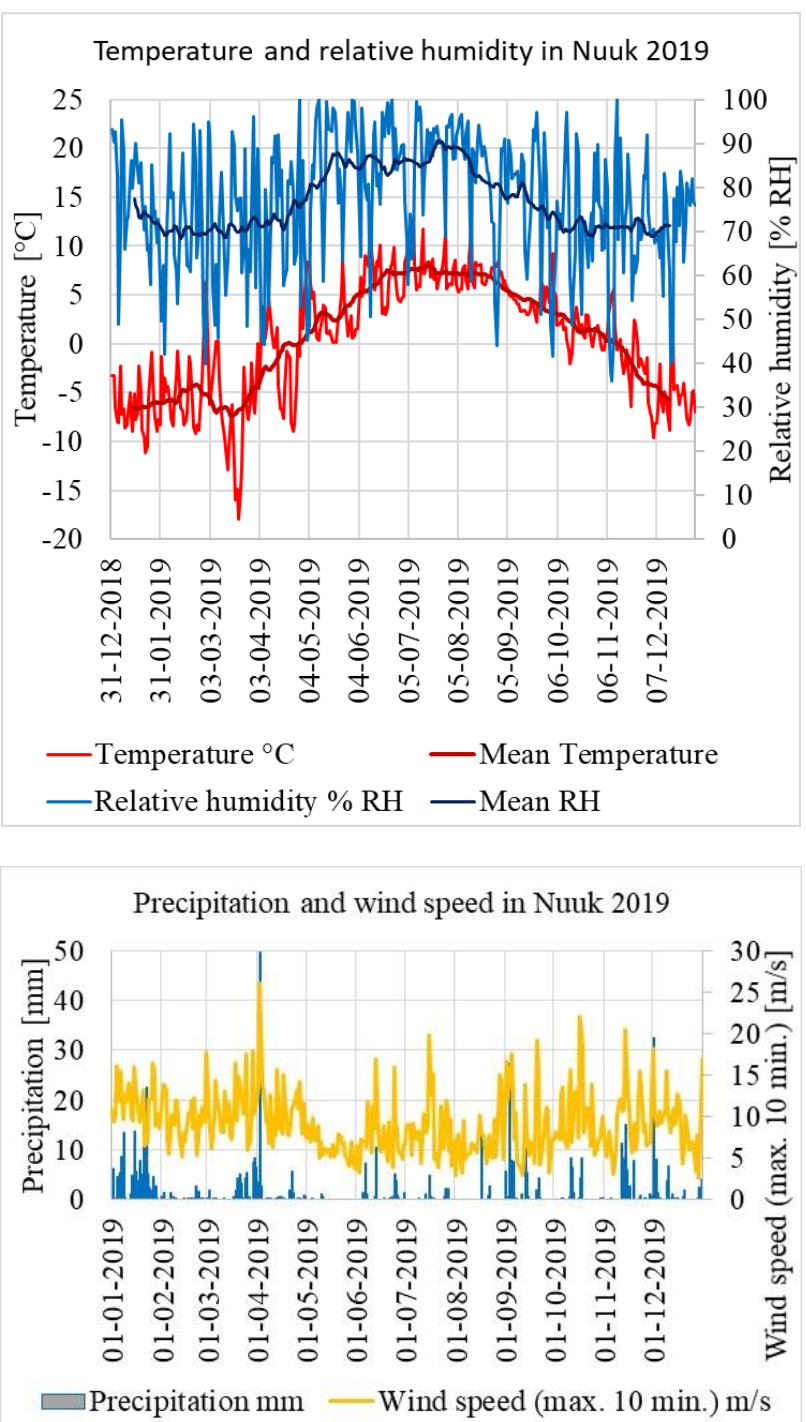

Fig. 1. Climate in Nuuk in 2019, based on information from [4]

Waiting for materials or manpower can stagger the time schedule for a construction decisively as the building period for some operations can be short, because of bad weather conditions in the winter. Using tents over buildings is not an option due to occasional storms.

Although Greenland has some resources such as metals and minerals, it has so far not been feasible to recover these. Therefore, most materials have to be imported. However, water, stones and gavel for concrete production are domestic; only the cement has to be imported. Consequently, concrete has become a popular building material.

\subsection{Building in Greenland}

Most houses in Greenland are relatively young, in 2000 less than $5 \%$ of the dwellings were more than 50 years old [6]. Traditionally houses were build and owned by the government or municipality, who preferred standard buildings, this meant that the building strategies have been controlled. Therefore, only few different types of buildings have been built in different periods with noticeable changes whenever there was a shift in paradigm. Table 1 gives an overview of typical building types for housing in towns over time, describing the characteristics in each period. Except for the first period, single-family houses are not considered in the table.

A shift in building style and strategy is normally caused by changes in society, these can be political or technical, and often a combination.

\subsubsection{Regulations, guidelines and traditions}

Although Greenland is a part of the Danish kingdom, it has its own building regulations [3], these are based on the Danish building regulations but adjusted to Greenland. Consequently, regulations on e.g. energy use differs from the demands in Denmark, while e.g. ventilation demands are similar. As Greenland is a small community there are very few specific guidelines for Greenland, and often Danish guidelines are being used as inspiration, although some adjustments must be made from time to time.

The chosen solutions are not only based on what is best in the Arctic, but also highly influenced by what the building industry is familiar with. The close connection to Denmark means that most architects and engineers are educated in Denmark. Consequently, many materials and methods are inspired by Danish building traditions. For example are concrete and timber widely used for load bearing elements, however, at the American Airbase in Thule steel frames are much more used. Illustrating differences in Scandinavian and American building tradition, applied to the same climate.

Table 1. Typical building styles in Greenland over time

\begin{tabular}{|l|l|l|l|l|}
\hline Period & \multicolumn{1}{|c|}{ 1950's } & \multicolumn{1}{c|}{ 1965-1975 } & \multicolumn{1}{c|}{ 1980-1990 } & \multicolumn{1}{c|}{ End 2010's } \\
\hline Style & $\begin{array}{l}\text { Small wooden standard } \\
\text { houses, Norwegian stile }\end{array}$ & $\begin{array}{l}\text { Prefabricated concrete } \\
\text { houses, with access } \\
\text { balconies }\end{array}$ & $\begin{array}{l}\text { Concrete houses with } \\
\text { wooden cladding } \\
\text { detached concrete houses } \\
\text { with fibre cement boards } \\
\text { as cladding }\end{array}$ \\
\hline Height & $1-2$ storey & 3-4 storey & $2-4$ storey & $4-7$ storey \\
\hline Photo & & &
\end{tabular}




\subsubsection{The building industry}

So far, the government or municipalities have financed most buildings. Updating building regulations have therefore not been that important, as the client could make specific demands, if the regulations were outdated or not specific enough for Greenlandic conditions. Therefore, it was possible to introduce new building strategies and thereby control the development in the building industry without changing the building regulations.

However, a new trend has started; developers are now erecting buildings that will be rented out on longterm contracts to the municipalities or government for housing. The prices the tenants pay for social housing are fixed per $\mathrm{m}^{2}$, but as there is a shortage of housing, the developers are able to rent out the apartments at a higher price per $\mathrm{m}^{2}$ than the municipalities or government can ask from the tenants. The only benefit for the municipalities or government is that they do not need the money up front for building the houses. In Greenland all land is publicly owned, the municipality can therefore not gain money from selling land, only issue area allocations; a specific Greenlandic phenomenon, where municipalities can give an applicant the right to use a specific piece of land. The trend of private development has started because the building industry is currently booming, resulting in prices that are too high for the municipalities or government.

Being in an island-operated area, the building industry is also affected; moving workforce and equipment is difficult. Consequently, the contractors are very few and often very local. Some of the Nuuk based contractors do have branches in other towns, but often there are very few contenders when a project is put up for tender. Consultants are less geographical locked.

With the relatively high-rise detached houses that were introduced in the late 2010s (see Table 1), based on the demands of the government, a new building style was introduced. However, as the market is booming, also other building styles are evolving, this paper describes different trends in building strategies that are currently seen in Greenland.

\section{Method}

To identify the current building strategies in Greenland, larger consultancies (architects and engineers) were interviewed, so was larger contracting companies. These were asked about their current projects and how they see the future for buildings in Greenland. Furthermore, different construction sites were visited and drawings from typical buildings procured.

Additionally, representatives from municipalities and government were interviewed about their plans for the future building strategies.

The interviews were made possible through a longterm commitment to the Greenlandic building industry, and consequently the interviewed persons felt free to discuss possibilities and obstacles for the Greenlandic building industry in the future.

\section{Different building strategies}

Focus of this paper has been on outer walls, as the main differences are in this area. Many problems are observed in crawl spaces and roofs, however, these are general problems and are so far not included in the shifts in building strategies. Crawl spaces are generally used because many buildings are placed on rocks; the ground level is seldom even and crawl spaces may differ in height. An alternative is to use columns, but crawl spaces are often preferred, as they to some extend can be used for storage, although some crawl spaces become very wet during spring when the snow melts.

Roof constructions are generally wooden rafters, and plywood as underlay for roofing felt. There is an ongoing discussion on whether roofs should be ventilated or not. One problem with ventilated roofs is, to prevent snow from entering the roof construction. However, this will not be discussed further in this paper.

From the investigation of different wall constructions, it became clear that in addition to the prevailing building method, there were several emerging building strategies.

\subsection{Traditional method}

The most common way to build multi-storey houses today is in-situ casted gables and inner walls, combined with filigree slabs. The facades consist of timber frames and columns with a filling of mineral wool, on the inside there is a vapour barrier, OSB boards and plasterboards, see figure 2 and 3.

At the outside, there are fibre cement based boards, mounted with special plastic beading or sealed to ensure tightness, in front of this there is a ventilated cladding of boards, these can be wooden, fibre cement based or based on compressed mineral wool. Figure 3 shows a detail of the façade. The gable has no vapour barrier or interior boards and the amount of insulation may be smaller, as the in-situ cast wall is relatively thick.

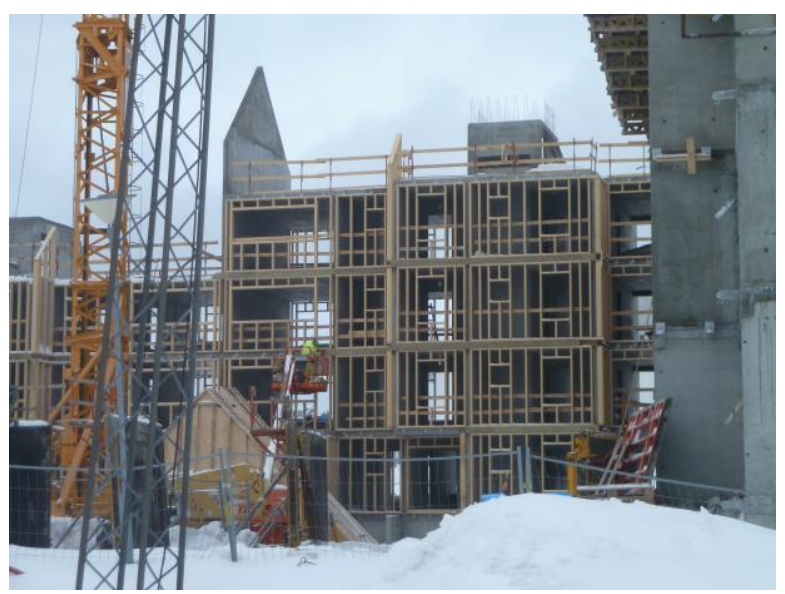

Fig. 2. Example where the traditional building method is used. Gables and interior walls of in-situ cast concrete, façade with timber frame 


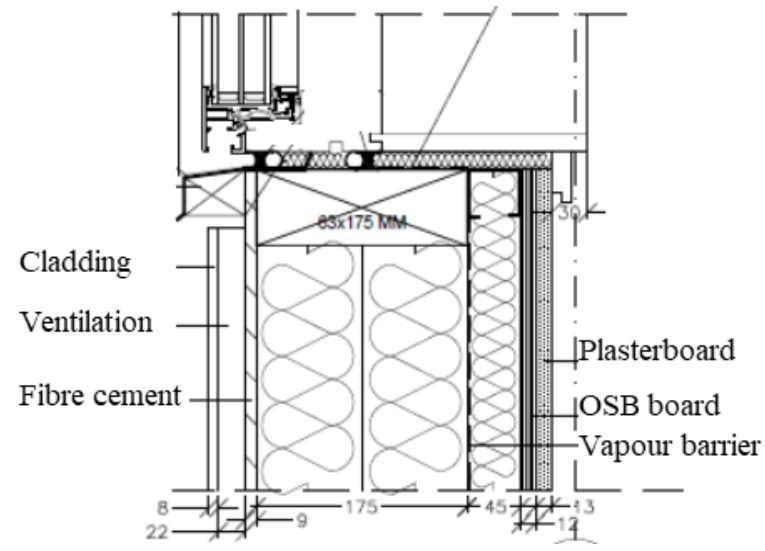

Fig. 3. Detail of façade built in a traditional way as an insulated timber construction with vapour barrier and wind barrier. There is special focus on tightening these barriers. From [7].

To protect against inclement weather, the wind barrier is installed early. Next the building is heated to dry out built in moisture. The building process generates a lot of moisture, as the inner walls, gables and top layer of the filigree slabs, which act as floor divisions, are all in-situ casted. It is therefore necessary to have a period where the building is heated for drying before the insulation and vapour barrier can be installed. This means high energy costs and long time of construction.

\subsection{Focus on non-organic materials}

Mould growth is a big problem in Greenland. To avoid this the government has a strategy of not using organic materials, as mould need organic material as nutrient to grow; mould growth is initiated and grows faster on substrates with easy assessable nutrients (e.g. wood) than on non-organic substrates (e.g. concrete) [8].

Compared to the traditional building method, this means that facades most be built differently; the timber construction must be substituted. One way is to use concrete for all outer walls and apply insulation directly to the outside of the concrete and finish with a ventilated cladding of compressed mineral wool, Figure 4 and 5 show an example.

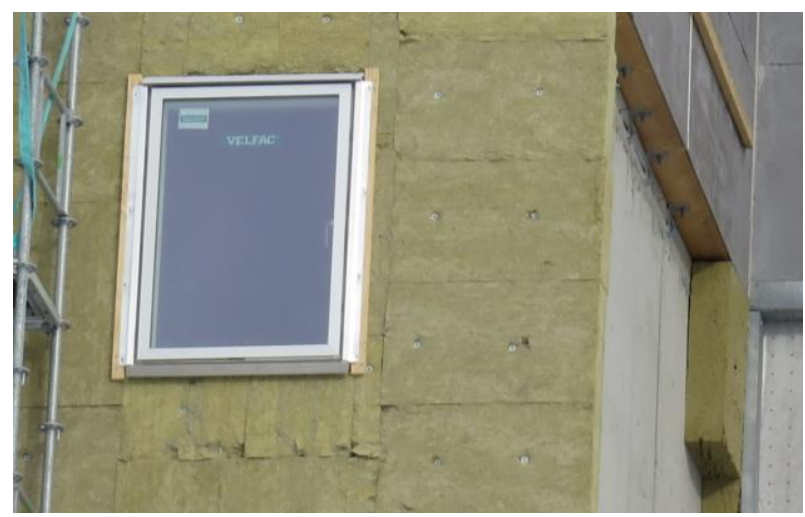

Fig. 4. Building with focus on non-organic materials; outer walls of in-situ cast concrete with mineral wool on the outside. Later a ventilated cladding was installed but no wind barrier.
Wooden elements were used in the roof construction; here the demand of no organic materials was given up.

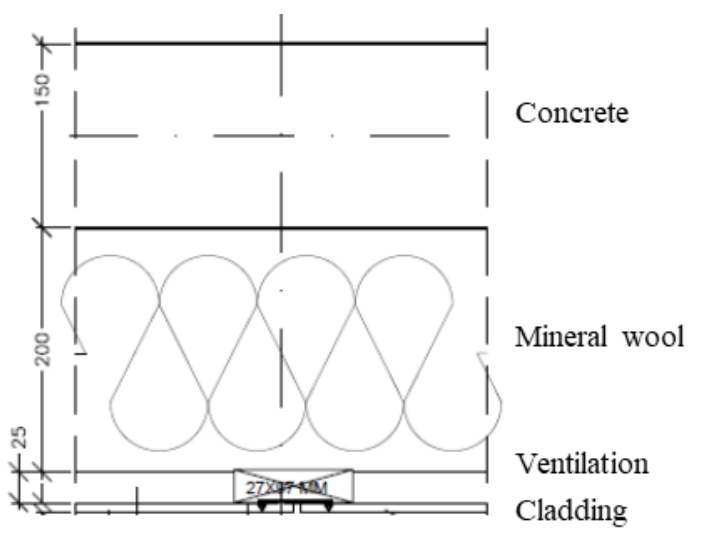

Fig. 5. Drawing of the outer wall, which is shown in Figure 4. From [9].

Figure 5 shows a wooden counter-batten, this was only used in the first two buildings of the shown project, later a steel based system was developed and used for the last two buildings to avoid any organic materials in the building envelope. Even the frames for mounting the windows were non-organic as these were made of compressed mineral wool. However, the windows were wooden.

The insulation system used here had flex zones that made it possible to press the insulation boards closely together. As the concrete walls must be considered airtight, and the insulation was directly fixed to it, a wind barrier was supposed to be unnecessary and therefore omitted following the description of the manufacturer.

\subsection{Focus on process}

Another way of reforming the prevailing building method is to focus on the process. The building season is short and traditional protection against inclement weather cannot be used. Furthermore, at the moment there is a lack of labour in most of Greenland, therefore, there is a request for a shift in building strategy towards processes that are less labour intensive - at least on site and that are faster or more robust toward inclement weather. The answer seems to be in using more prefabricated elements that can be manufactured indoors in the winter and are fast to install on site.

Attempts to make more use of prefabricated elements have been made, e.g. precast hollow floor elements have been shipped from Europe or Iceland to Greenland. Floor elements can be placed on flat racks and the transportation costs are therefore not as high as if, they should be transported in containers. Wall elements cannot be transport on flat racks and are too high to be placed in ordinary containers.

The idea of minimising the work on site has been used before by the former Danish governmental organisation Greenlandic Technical Organisation (GTO). GTO planned a series of wooden single-family houses that were mainly built until the 1970 s, when the market 
became more open [6]. The houses were planned as building kits, which were shipped from Denmark and only had to be assembled on site.

Today this has been taken even further, as an emerging building strategy is to build with Cross Laminated Timber (CLT) elements as shown in Figure 6.
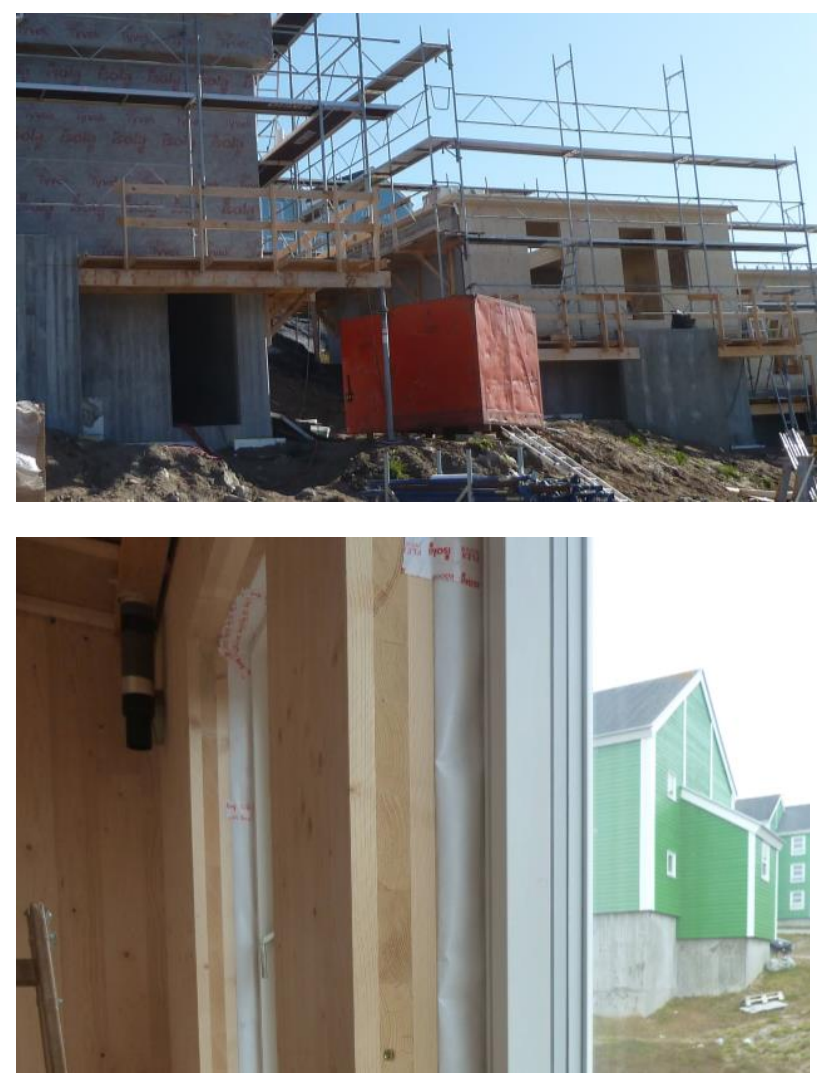

Fig. 6. Two storey double family houses built with CLT elements. The upper photo shows different stages of the process, to the right the raw CLT elements, to the left a diffusion open foil covers the CLT elements before the insulation is mounted. Below is a photo of the inside of the house before the lining is installed.

The wall construction is similar to what is shown in Figure 5, except for the concrete that has been changed to CLT elements. Furthermore, there is a diffusion open foil between the insulation and the CLT element. The purpose of foil is to protect the CLT elements against precipitation until the insulation and cladding is installed.

The use of CLT elements goes against the idea of not using organic materials. However, there are also strategies of using small elements of non-organic material, e.g. steel frames and building envelope of PUR foam covered by steel plates or fibre cement based boards, as shown in Figure 7. These are mainly used for single-family houses.

\section{Discussion}

The different building methods all have their pros and cons, and there is probably no single answer to which method is the best, as it depends on the agenda of the person who answers the question.

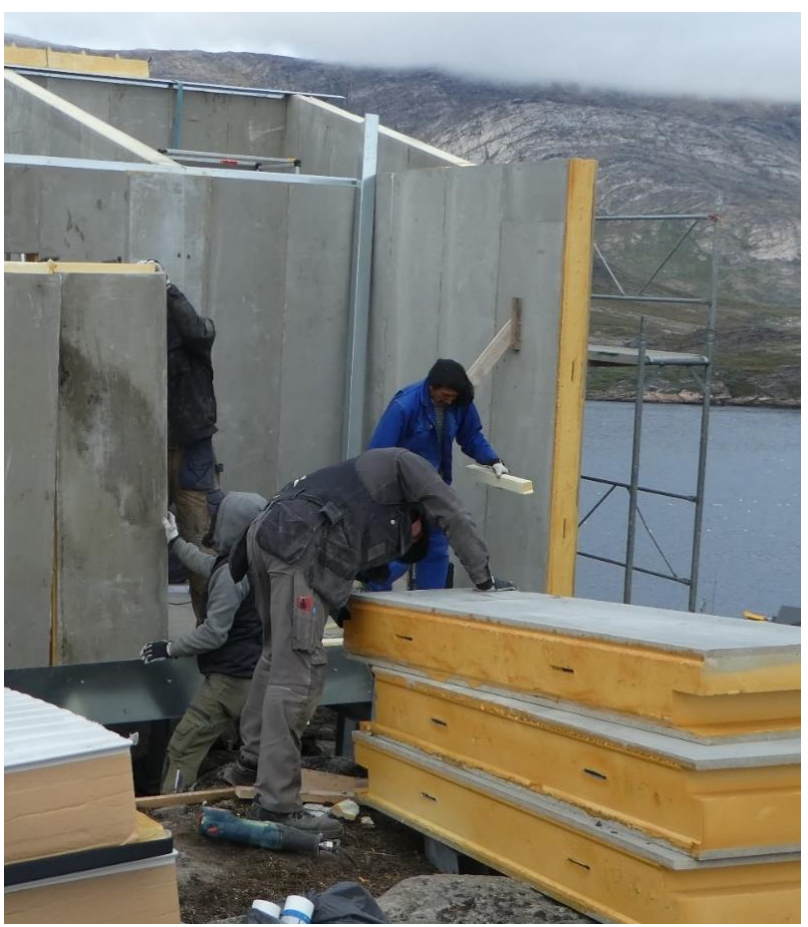

Fig. 7. Single-family house made of non-organic materials.

For some the health aspect may be the most important, for others aspects of sustainability, comfort, economics, social responsibility etc. may be more important. Focus in the discussion here, is on hygrothermal performance and mould growth, other aspects will however also be mentioned.

\subsection{Building strategies in general}

The reason for building houses is to obtain a comfortable and healthy indoor climate. To obtain this, buildings should be tight against precipitation and ensure temperature and relative humidity that do not cause moisture damage including mould growth, as these could damage materials or the health of the building users.

One way to determine how different building strategies perform hygrothermally is to measure temperature and relative humidity indoors, outdoors and in several points inside the building envelope. Although simulations may be useful in predicting behaviour this is not always enough, as some methods are more robust towards mistakes made on site than others, this robustness may not be found in simulations, as these normally consider details as they were planned. However, placing sensors in walls will only tell the hygrothermal conditions in one single point and this may not be in the area where a mistake was made on site, the mistake may be located one meter away and is then unlikely to be discovered by the measurements.

\subsubsection{Robustness}

A project, built according to the strategy presented in section 3.2, was investigated because inhabitants complained about having difficulties heating the apartments. The investigation showed several mistakes, however, one problem stood out as it was a consequence 
of the building strategy not being robust. Placing relatively hard mineral boards on an in-situ cast concrete surface will result in voids between insulation and concrete due to the unevenness of the concrete surface, especially where floor divisions and walls meet. If the insulation boards are not fitted tightly to each other, air might penetrate the insulation and cool the concrete surface as the air can move in the void behind the insulation board. As can be seen from Figure 4, the insulation boards were not tight fitted.

This phenomenon could not be seen in simulations. Neither could it have been discovered by sensors, placed in the building envelope, unless the problem by chance had happened near the sensor. Furthermore, a similar construction was mounted in a test building with sensors monitoring temperature and relative humidity. Unfortunately, the in-situ cast concrete was replaced by several layers of fibre cement based boards. This was done for economical reasons. In this case, the surface was smooth and the risk of having wind, cooling the surface was therefore minimal. Therefore, the test site would not reveal the weakness.

The only test that revealed the problem was therefore a full size testing with users as sensors.

The buildings made with CLT elements as described in section 3.3 had a similar insulation system. It will be interesting to see, if the inhabitants expect similar problems or the smooth surface of the CLT elements makes this solution more suitable in these cases. So far no problems have been reported.

The described problem is probably not only a problem in Greenland, however, the Greenlandic climate with low temperatures combined with heavy storms, magnifies the problem, and thereby reveals lack of robustness faster than milder climates.

\subsubsection{Mould growth}

Mould growth can only take place if there are nutrients available, however, mould only need very small amounts of nutrients. In milder climates it is not uncommon to see mould growth on brick or concrete walls if these are cold or moist e.g. in corner near ground level or behind furniture placed close to an outer wall. Mould may live on dust, if the temperature and relative humidity are within certain thresholds. Focussing on nutrients is therefore unlikely to solve problems with moulds, although a non-organic construction may be more robust than one containing wood, cardboard or paper.

Furthermore, it can sometime be difficult to determine whether a material contains nutrients for mould, e.g. mineral wool is non-organic, however, the glue that it contains could act as nutrients. If it is a requirement that materials cannot contain nutrients, there must also be a test. Such tests do exist, e.g. as stated by [10]. However, these are so far seldom used, and cannot be used on material type level, e.g. mineral wool in general, but only on specific materials e.g. mineral wool from a specific manufacturer.

Additionally, it should be considered where the material is being used. If e.g. it is used as battens on the outside, the risk of mould growth being harmful to the user of the building is minimal.

Consequently, limiting the use of organic materials can be helpful, but if it means new methods, that are less robust towards workmanship, it could be more important to use known methods where the chances for having hygrothermal conditions below the threshold for mould growth are bigger.

\subsection{Special Greenlandic issues}

While the technical problems in the different building strategies are likely to be the same in the Arctic region as - to some extent - in milder climates, some issues relate especially to Greenland.

\subsubsection{Political issues}

Being a small community where most building activity used to be initiated by the government or municipalities means that the building strategies have been controlled by the government, which entails that building strategies have not only been ruled by technical and economic issues but political concerns have also played a role.

For example is there a political wish to use the workforce more effectively, this means:

- Ensure building activity in the winter

- Employ less-skilled workers in the building industry to ease the need for skilled workers

- Reduce the need for housing by building more dwellings faster and cheaper

One way to fulfil all these is to use prefabricated elements, and as the current strategy is to avoid organic materials, this mainly means precast concrete. However, transportation of precast concrete is difficult in Greenland. Furthermore, lifting gear may not be available.

Nevertheless, at the moment one contractor is building a factory in Nuuk for manufacturing precast wall elements, hoping hereby to fulfil the requirements of the client, when this is the government or municipality. In Sisimiut a project is being build with precast elements, which are manufactured more or less in a tent on site.

These emerging initiatives will give some experience on what is possible, although it is to be expected that there may be some difficulties in the beginning. Using precast elements from Europe or Iceland is not a solution to the goal of using Greenlandic workforce.

\subsubsection{Sustainability}

What is sustainable depends on the location, therefore different sustainability standards are adjusted to different locations. So far, there has not been made standard for Greenland, however, it is expected that it would be very different from e.g. European standards as the availability and transportation of goods is so different in Greenland compared to Europe. For example did the government ask for locally produced precast concrete elements in a 
project called "Sustainable dwellings" because locally produced concrete was considered to be more sustainable than e.g. imported timber. However, no calculations were made on this. There is a need for a standard to assess sustainability in Greenland to be able to compare different building strategies in respect to sustainability.

\subsubsection{Maintenance}

Durability and maintenance are part of sustainability calculations. Unfortunately, maintenance has for many years not been prioritised very highly in Greenland. Instead of making plans for maintenance and follow them, buildings have for many years been used as they were and discarded when the standard became too low. Twenty years ago the average service life of buildings was 25 years [6]. It might have improved, but the awareness of a need for maintenance plans is still limited.

There are probably several reasons why maintenance has low priority, one of the reasons may be that maintenance work can be difficult to perform, as the combination of harsh climate, accessibility and lack of skilled workers makes it challenging. In addition, there is a shortage of dwellings and every year $40 \%$ of the population moves [1]. Consequently, the need is high but the motivation for doing maintenance work or taking care of a building is limited.

To reduce the need for maintenance, focus is on using durable materials, e.g. as alternatives to the traditional colourful wood cladding that must be repainted regularly, fibre cement based boards that look like painted wood or colourful compressed mineral wool boards have become popular, see Figure 8 .

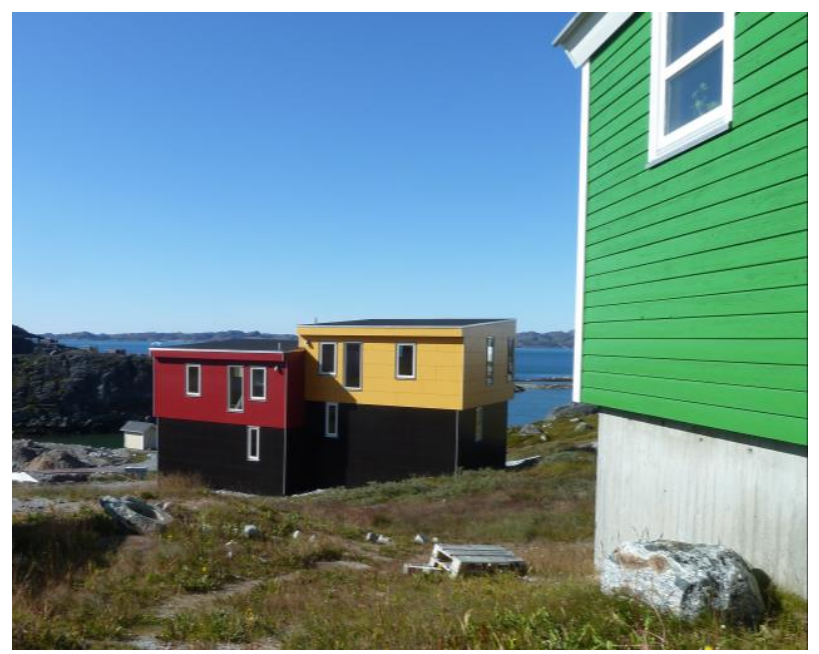

Fig. 8. To limit the need for repainting, alternatives to the traditional colourful cladding (in the front) have become popular; here coloured compressed mineral wool boards cladding for double family houses made of CLT elements, same projects as in Figure 6.

Storms, where dust and ice particles hit surfaces, accelerate the abrasion of paint or other surface treatments, are one of the reasons why service life of surface treatments is low. When this is combined with low maintenance, the risk of damage below the surface increases.

\subsubsection{Greenland as test site}

The harsh climate, including many sudden changes from frost to thaw, is not only less forgiving than more temperate climates towards faults in the design or workmanship, it is also challenging for the surface of materials. Therefore, Greenland can be used as test site for constructions and materials, as an accelerated test for materials planned for use in milder climates.

This is contrary to what is normally considered; according to Arrhenius' law, increasing temperature will increase chemical degradation processes exponentially [11], therefore accelerated degradation testes are normally performed at elevated temperatures. Degradation tests performed in Greenland will therefore not cover all degradation mechanisms but mainly mechanical ones, and it must be considered to do supplementary testing if chemical reactions are to be tested.

\section{Conclusion}

Currently there are three main building strategies in Greenland:

- The well-tested method with in-situ cast concrete combined with wooden frame and studs. A method the workers are familiar with, and that generally is a safe solution. However, the method is time and energy consuming.

- A method where focus is on using non-organic materials to prevent mould growth. However, mould may grow on dust and if the hygrothermal conditions favour mould growth the method is only little less susceptible to mould growth than methods that include e.g. wood.

- A building strategy that focusses on the building process, mainly by using prefabricated elements to speed up the process and thereby close the building fast to prevent intruding precipitation. This strategy is evolving but is challenged by the difficulty in transporting prefabricated elements in Greenland.

The climate in Greenland is a challenge, however, the main problem is the building process, not so much the design, as in theory many solutions will work. Nevertheless, to some extent, building design governs the process e.g. use of prefabricated elements, constructability and thereby robustness towards bad workmanship.

\section{References}

1. Greenland in figures: http://www.stat.gl/publ/en/GF/ 2019/pdf/Greenland\%20in\%20Figures\%202019.pdf 
2. Homepage of Qeqqata municipality: http:// qeqqata.odeum.com/

3. Greenlandic building regulations 2006: Ineqarnermut Attaveqarnermullu Pisortaqarfik: http://www.byginfo.gl/Portals/0/pdf/love/BR2006D K.pdf

4. Danish Meteorological Institute weather Archive: https://www.dmi.dk/vejrarkiv/

5. Homepage of the Greenlandic utility company Nukissiorfiit: https://www.nukissiorfiit.gl /om-os/

6. J.C. Madsen: Grønlandske boliger - selvbyggeri og typehuse (in Danish), Atuagkat, Viborg, Denmark (2000)

7. Clement \& Carlsen: Drawings from Tuujuk, Nuuk, (2016)

8. K. Sedlbauer. Vorhersagen von Schimmelpilzbildung auf und in Bauteilen, Ph.d. Thesis, Lehrstuhl für Bauphysic, Stuttgart (2001)

9. Clement \& Carlsen: Drawings from 48 alsidige boliger, Nuuk, (2015)

10. P. Johansson, A. Ekstrand-Tobin, G. Bok. Building and Environment 81: 404-409. (2014)

11. B.P. Jelle,J Mater Sci 47:6475-6496(2012) 